\title{
Analysis of results of emission parameters of advertising media in field conditions
}

\author{
Marcin Chrzanowicz ${ }^{1, *}$, and Piotr Jaskowski ${ }^{2}$ \\ ${ }^{1}$ Warsaw University of Technology, Faculty of Electrical Engineering, Plac Politechniki 1, 00-661 \\ Warsaw, Poland \\ ${ }^{2}$ Warsaw University of Technology, Faculty of Transport, 75 Koszykowa st., 00-662 Warsaw, Poland
}

\begin{abstract}
The lighting parameters of advertising media observed from the road leading drivers are one of the basic factors which should be taken into account in the process of determining the influence of the carrier on the risk related to the possibility of a road event. As a result, exceeding the permissible parameters may lead to disturbance of the vision process or distraction from the driver's primary objective, which is to observe the road situation. The article presents the results of tests of lighting and geometric parameters carried out on a large number of advertising media located in the vicinity of Polish roads. The study was conducted at night, using an original research procedure. Observation of advertising media from the driver's position is included. The final result of the work is information about the actual levels of lighting parameters generated by a large group of advertising media of different character of light beam emission (broken down into defined emission groups A - D), which can be observed from the driver's position.
\end{abstract}

\section{Introduction}

The lighting parameters of advertising media observed from the road by drivers are one of the basic factors that should be taken into account when determining the impact of the media on the risk related to the possible occurrence of a road event [1,2]. Measurement of important technical and lighting parameters, their collection, cataloguing and analysis are crucial to determine the permissible ranges of variability and to indicate the prohibited values. Conducting field research on advertising media involves numerous restrictions resulting from the existing measurement conditions, location, geometric and emission parameters of the media itself and the environment in which it occurs. The developed procedure $[3,4]$ used to measure emission parameters takes into account the listed factors and enables unambiguous identification of the limit values of the measured parameters.

Negative lighting effects of advertising media on drivers may result in a traffic hazard [57]. This hazard may be due to excessive luminance or contrast within the driver's field of vision. As a result, exceeding the limit values may lead to abnormal vision or distraction of the driver from the primary objective of observing the driving situation.

\footnotetext{
${ }^{*}$ Corresponding author: marcin.chrzanowicz@ee.pw.edu.pl
} 
The main aim of the research issue discussed in the article is to perform lighting measurements of a large group of advertising media and to search for links between the light and photometric values and their influence on possible disturbances of the driver's vision process.

\section{Field research of a selected group of advertising media}

A group of media containing advertising representatives with different methods of light beam emission (group "A" - light source, group "B" - frontlight, group "C" - backlight, group "D" - without backlighting) was selected for the field research. Each advertising medium was visible from the roadway. The choice of location served to present the problem of the impact of advertising in different regions of Poland.

\subsection{Location of advertisement tested}

A total of 339 media were measured. In order to select a representative group, the measurement results for 230 advertisement were evaluated further. The measurements were taken at night, in good weather conditions for three locations: Gdańsk - Tczew, Warsaw Brand name and Łomianki.

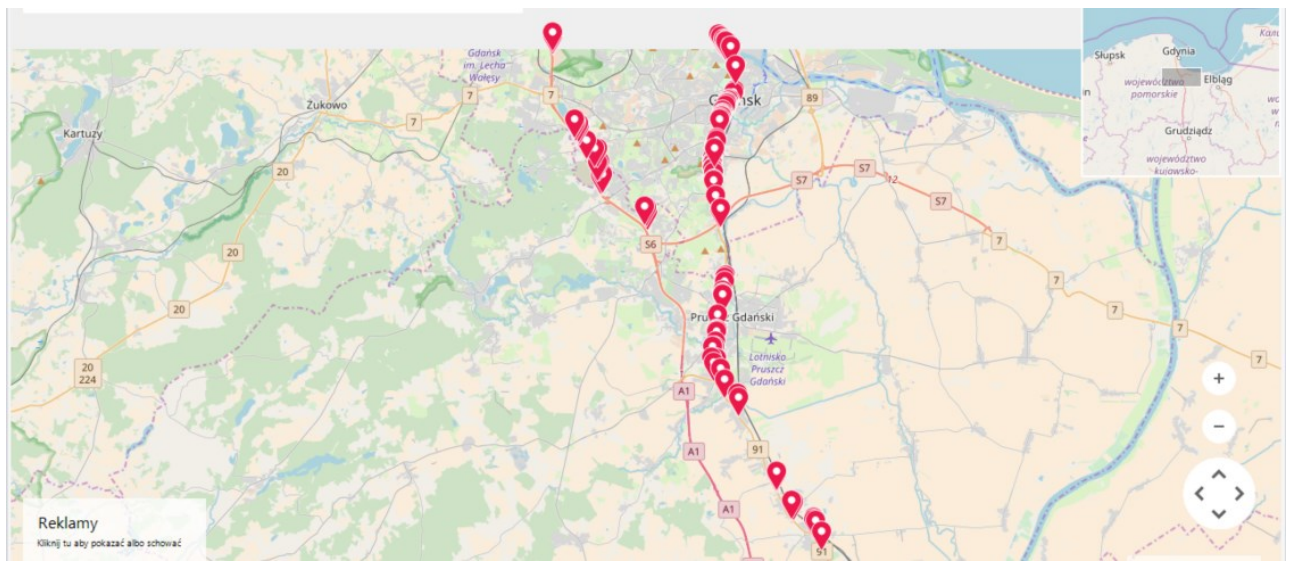

Fig. 1. Example of an advertisement location on the Gdańsk - Tczew route. Source: Own calculations based on [8].

\subsection{Photometric parameters to be tested}

The measurement data consist of the following characteristics of the advertisement:

- classification according to the light emission splitting exercise,

- the geometric dimensions,

- angle of the advertisement's setting in relation to the road axis,

- the operating distance,

- maximum luminance of the surface of the $\mathrm{L}_{\mathrm{Nmax}}$ advertising medium $\left[\mathrm{cd} / \mathrm{m}^{2}\right]$,

- average luminance of the background around $\mathrm{L}_{\mathrm{Tśr}}\left[\mathrm{cd} / \mathrm{m}^{2}\right]$,

Additionally, a contrast of the luminance of the advertising surface with the background, which is a ratio of the difference of the luminance of the observed object and the background luminance to the background luminance, was calculated for each medium on the basis of the obtained data. The luminance contrast [3] can be calculated from formula (1): 
where:

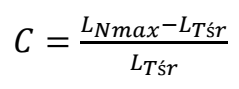

$C$ - luminance contrast,

$L_{N \max }$ - the maximum value of the luminance of the advertising medium $\left(\mathrm{cd} / \mathrm{m}^{2}\right)$,

$L_{T \prime s}$ - the mean value of the ambient luminance, background of the advertising medium $\left(\mathrm{cd} / \mathrm{m}^{2}\right)$.

\subsection{Methodology used for the measurements}

In order to perform the measurements of lighting and geometric quantities, the author's research procedure $[3,4]$ was applied, the most important assumptions of which are as follows:

- measurement in favourable meteorological conditions (no rainfall, ambient temperature within the range permissible for measuring instruments, good atmospheric transparency),

- measurement from the direction of maximum light beam emission - perpendicular to the position of the advertising medium (Fig. 2),

- measurement distance depending on the size of the measuring field in order to ensure discreetness of the media surface at the level of 1/100 of its geometric dimensions (the measurements used a matrix and a point control meter with a variable measuring field from $6^{\prime}$ to $3^{0}$ ),

- for safety reasons, measurement from the edge of the road and not from the eye of the driver of the vehicle, but at the correct height of $1,5 \mathrm{~m}$ above the road surface.

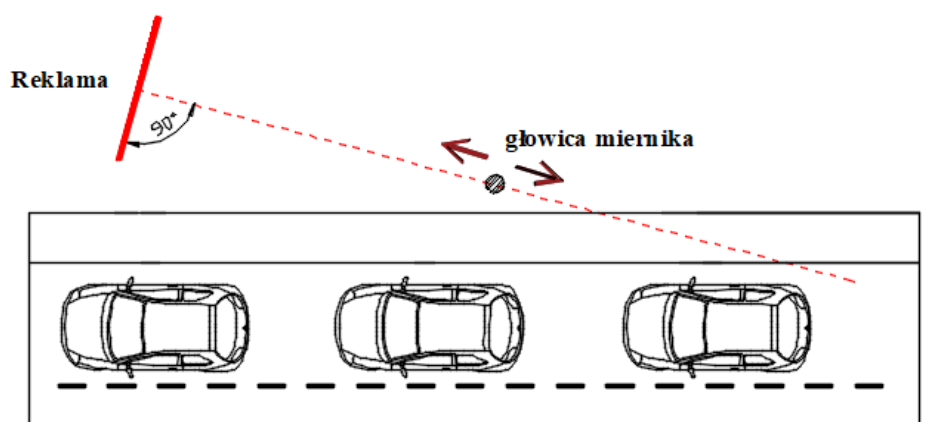

Fig. 2. Location of the meter head in relation to the advertising medium. Source: own elaboration.

Selection of the measurement fields for $L_{N \max }$ of the media surface and the $L_{T \text { śr }}$ of the observation background (the media environment) using a CCD matrix meter is shown in Figure 3. 


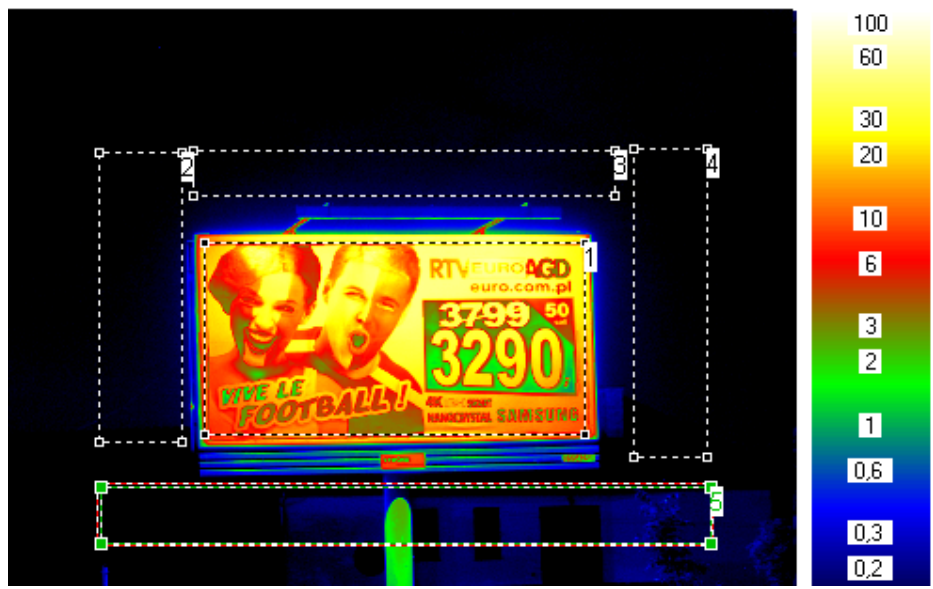

Fig. 3. Measurement of luminance parameters of the advertising carrier and the background of the observation. Source: own elaboration.

\section{Results of measurements of lighting parameters of advertising media together with analysis of collected data}

The results of lighting and geometrical measurements were collected in a database and subjected to statistical analysis. Table 1 shows the average size for all media groups: maximum media luminance $\left(\mathrm{L}_{\mathrm{Nmax}}\right)$, area, and contrast $[\mathrm{C}]$. The standard deviation of the spread width of the measured values in relation to the mean is given. Additionally, the luminance value of the mean background $\left(\mathrm{L}_{\text {Tśr }}\right)$ was determined. It is clear from the data that the most negative impact on the driver in terms of dazzling potential is exerted by advertisements in the "A" and "C" groups. They also generate the highest contrast. However, ads in the "A" group have the smallest surface area and the largest statistical spread of medium contrast. It may happen that despite the high luminance value of the surface and the contrast, the advertisement will have a small impact due to its small surface area and small angular size. Conversely, reverse situations are also possible (low luminance and contrast, but large surface and angular sizes - e.g. group "B"), which may be underestimated by researchers and, as a result, become a road traffic hazard.

Table 1. Result of measurements of lighting parameters of advertising media.

\begin{tabular}{|c|c|c|c|c|}
\hline \multirow{2}{*}{} & \multicolumn{4}{|c|}{ classification by emissions-related sharing } \\
\cline { 2 - 5 } & A & B & C & D \\
\hline number of advertisement & 34 & 108 & 65 & 23 \\
\hline mean maximum luminance $\mathrm{L}_{\mathrm{Nmax}}\left[\mathrm{cd}^{\mathrm{n}} / \mathrm{m}^{2}\right]$. & 101.22 & 43.17 & 69.78 & 6.84 \\
\hline standard deviation & 11.5 & 2.16 & 4.25 & 3.59 \\
\hline average geometric surface $\left[\mathrm{m}^{2}\right]$. & 5.77 & 19.2 & 12.62 & 18.36 \\
\hline standard deviation & 2.03 & 1.03 & 1.89 & 4.18 \\
\hline average contrast $\mathrm{C}[-]$ & 305 & 204.44 & 282.54 & 37.6 \\
\hline standard deviation & 72.54 & 19.24 & 35.88 & 18.5 \\
\hline luminance mean background $\mathrm{L}_{\mathrm{Ts}}\left[\mathrm{cd} / \mathrm{m}^{2}\right]$. & 1.04 & 0.47 & 0.7 & 0.25 \\
\hline
\end{tabular}


Figures 4 - 7 show the statistical relations between the lighting and geometric values of advertisements. This approach is justified by the fact that the driver's overall glare impression is a component of luminance, contrast and angular size.

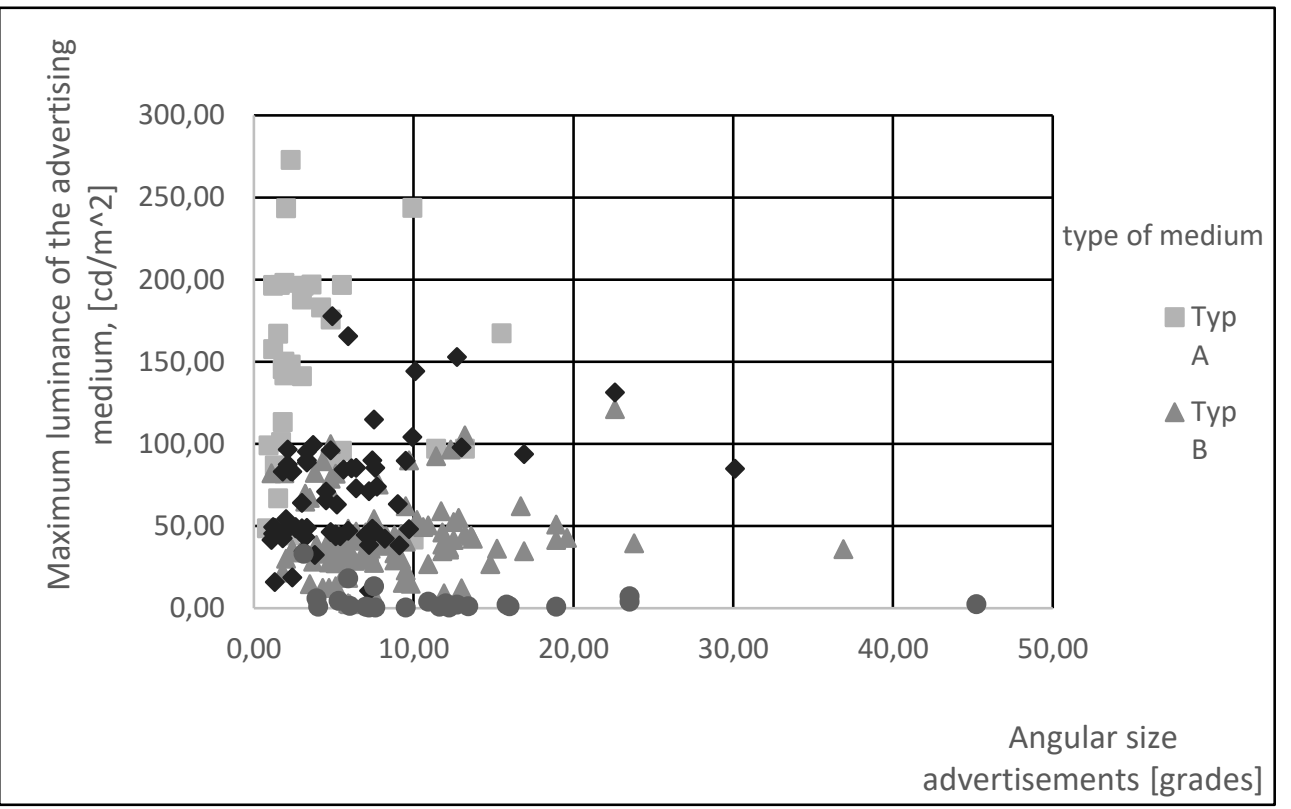

Fig. 4. Maximum luminance of the advertising medium depending on the angular size and type of the medium. Source: own elaboration.

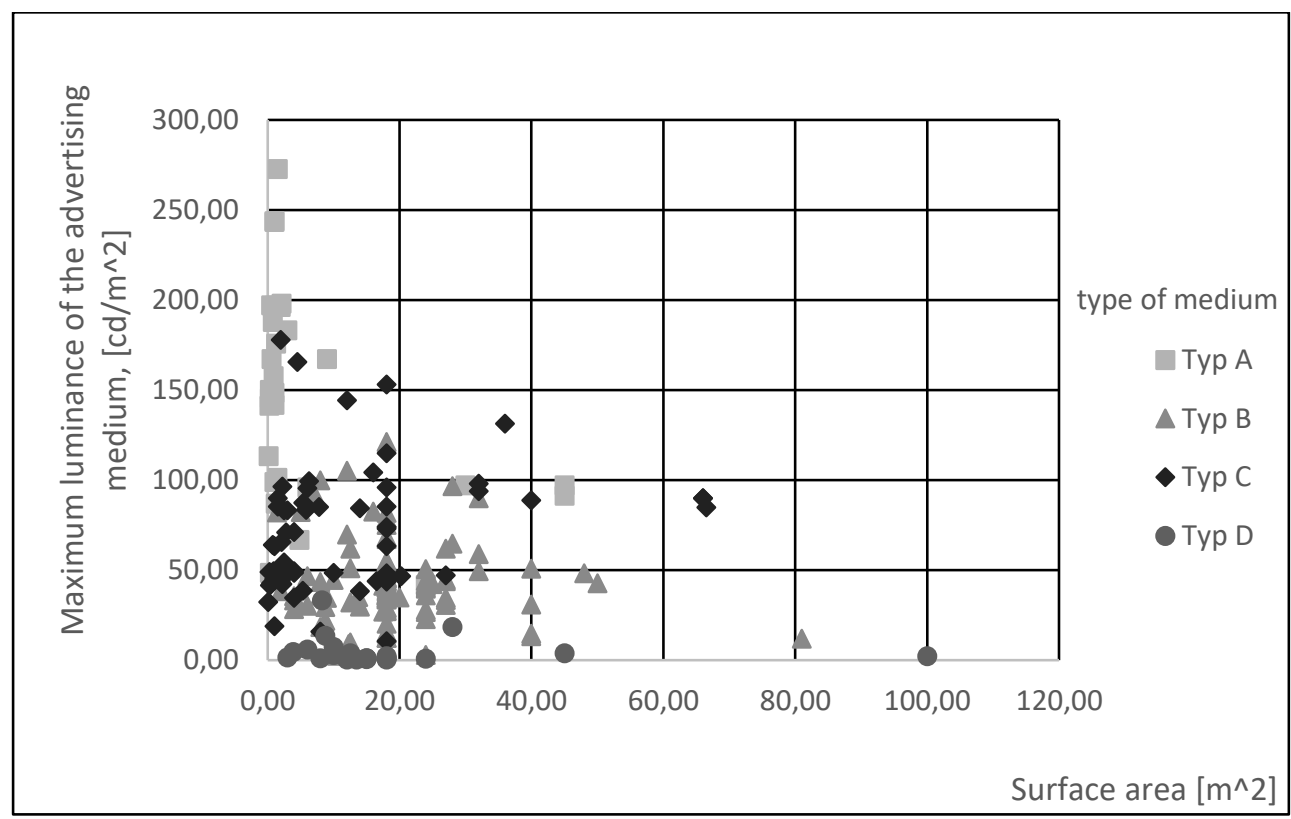

Fig. 5. Maximum luminance of an advertising medium depending on the surface and type of medium. Source: own elaboration 


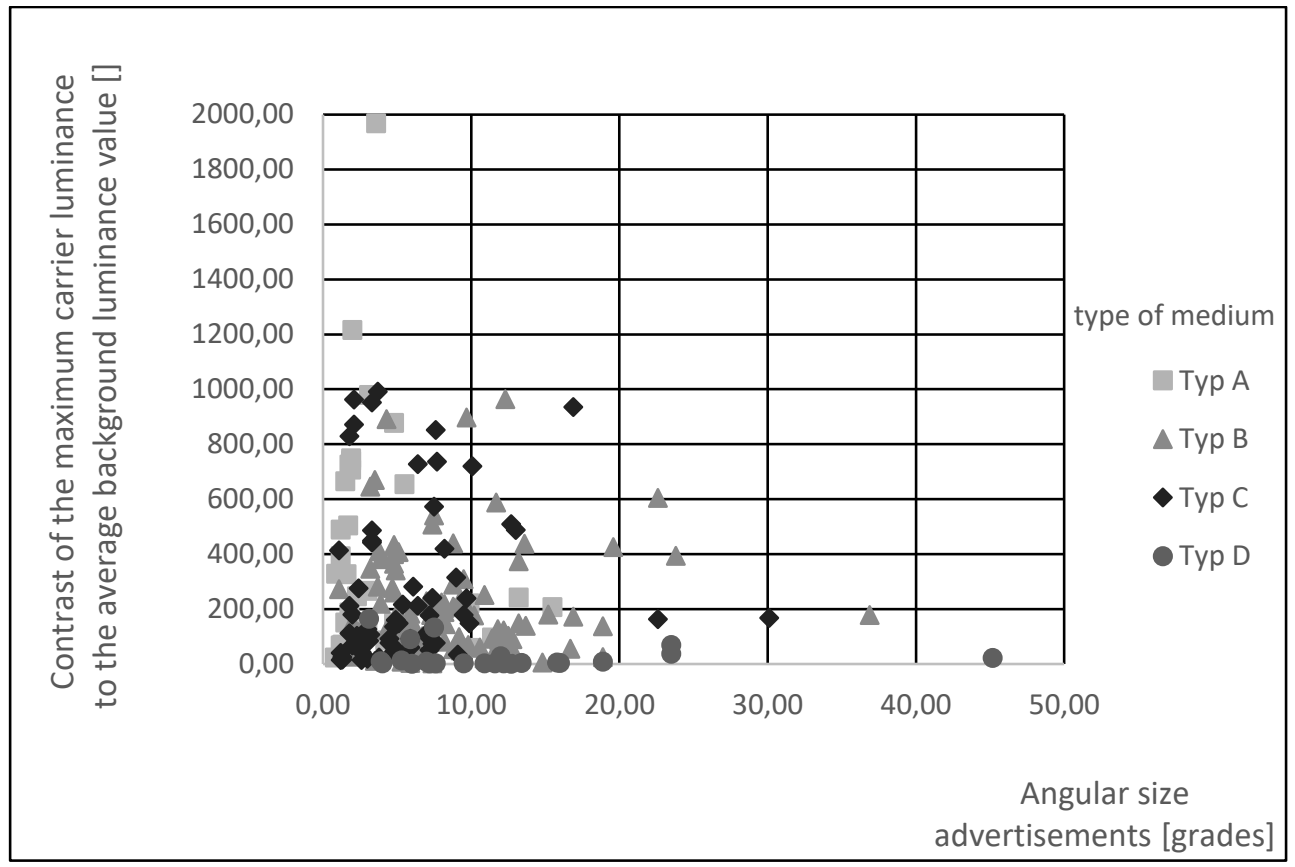

Fig. 6. Contrast of luminance of maximum advertising media depending on the angular size and type of media. Source: own elaboration.

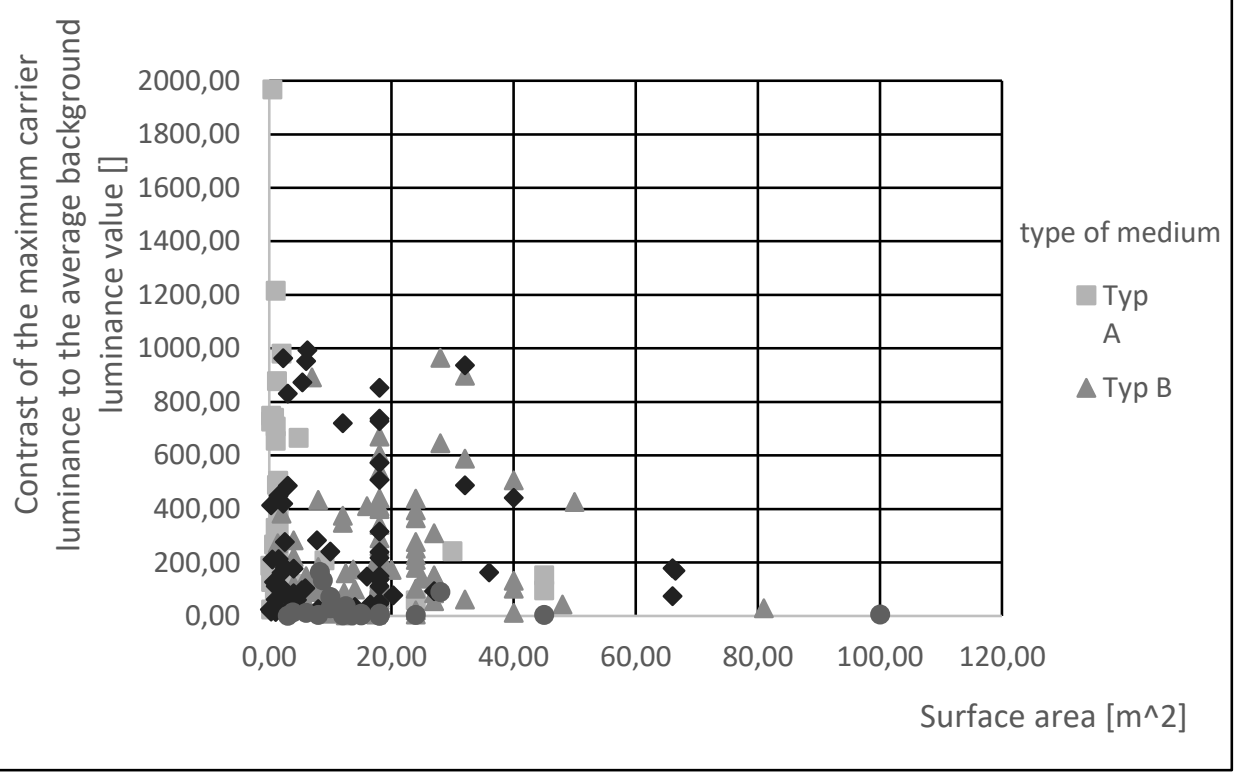

Fig. 7. Contrast of luminance of maximum advertising media depending on the surface and type of media. Source: own elaboration

In the opinion of the authors of the publication, the photometric values that characterise an advertising medium should relate to the geometric surface and the size of the angular advertisement as seen from the driving position of the passenger vehicle. Advertisements with high maximum luminance are usually of small angular size (small area, setting at a small 
angle to the road) - Fig. 4.5. The same applies to contrast analysis (Fig. 6.7). Lighting guidelines, apart from limiting the lighting parameters, should define precise geometrical values. When an advertisement is of high quality $\left(L_{\text {Nmax }}\right)$ it should be small in size and placed as parallel to the road as possible.

\section{Summary}

The studied advertising media did not exceed the level of $250 \mathrm{~cd} / \mathrm{m}^{2}$ for maximum luminance. The Landscape Act [9] allows for: $600 \mathrm{~cd} / \mathrm{m}^{2}$ at night in a built-up area and $400 \mathrm{~cd} / \mathrm{m}^{2}$ outside a built-up area. Despite the relatively low level of brightness, some media had a negative impact on the driver, which was caused by the high contrast between the luminance of the advertisement and the background (advertising located in a dark environment) and a large angle to the road (setting close to perpendicular), which significantly increased the angular size of the object and thus the value of the luminance of mist affecting the level of glare. The analysis of the research results has shown unequivocally that there are situations in which the maximum luminance levels adopted in the Landscape Act are too high. The guidelines should refer very precisely to the illumination level of the background observation in the advertising environment. Large-format advertising should have a stricter criterion for acceptable luminance levels because of its large angular size. The research also confirmed that advertisers largely complied with the provisions of the Landscape Act and reduced the levels of brightness (luminance) of the visual information carriers (the attention concerns mainly advertising from the "A" group - LED telebims). Further research works are indicated and are to result in precisely defined lighting, geometric and location guidelines for advertisements, which reduce the negative impact of advertisements on the driver's vision process. Defined permissible levels of technical parameters and repeatable measurement procedures will allow for effective control and verification to eliminate road traffic hazards generated by advertising seen from the road.

Issues presented in this article are the subject of research and analysis in a project carried out by the Faculty of Transport of the Warsaw University of Technology entitled: The impact of advertisements on the level of road traffic safety, contract number: DZP/RID-I-33/4/NCBR/2016 (Registration of Road Innovation), financed by the National Centre for Research and Development and the General Directorate for National Roads and Motorways.

\section{References}

1. S. Speirs, A. Winmill, T. Kazi, The Impact of Roadside Advertising on Driver Distraction: Final Report (WSP Development and Transportation, Basingstoke, 2008)

2. P. Tomczuk, P. Jaskowski, Luminance measurement selected advertising signs located in a lane, Pr. Nauk. Politech. Warsz. Transp. 108 pp. 95-107 (2015)

3. M. Chrzanowicz, P. Tomczuk, P. Jaskowski, Methodology of Measuring the luminance surface advertisting media which emits lights, Pr. Nauk. Politech. Warsz. Transp. 118 pp. 49-60 (2017)

4. M. Chrzanowicz, P. Tomczuk, Research on the parameters of light emitting advertising media, MATEC Web Conf. 122 pp. 03002 (2017). doi:10.1051/matecconf/201712203002

5. Deparment of Transport United Arab Emirates, Roadside advertising manual, Document No: AD-R-03 First Edition (Abu Dhabi, 2013)

6. K. Domke, M. Zalesińska, Wielkoformatowe elektroniczne reklamy a bezpieczeństwo użytkowników ruchu drogowego, Logistyka. 3 pp. 1351-1361 (2014) 
7. Illuminating Engineering Society of North America, TM-11-00, Light Trespass: Research, Results, and Recommendations (New York, USA, 2000)

8. Google Maps. Available at: https://www.google.pl/maps/ Accessed: 2018-04-25, (2018)

9. Act of 24 April 2015 amending certain acts on strengthening the tools for landscape protection, OJ 2015 Pos. 774 (Poland, 2015)

10. T. Mackun, K. Jamroz, J. Żukowska, J. Rychlewska, Zagrożenia dla uczestników ruchu drogowego stwarzane przez reklamy widziane z drogi, Drogownictwo. 4-5 pp. 134141 (2015)

11. M.W. Tantala, P.J. Tantala, An examination of the relationship between advertising signs and traffic safety, in: 84th Annu. Meet. Transp. Res. Board, (TRB, Washington D.C., 2005) 